\title{
Effect of dried ethanol extract of arbutin-containing leaves from Artocarpus on tyrosinase inhibition and postharvest preservation
}

\author{
Sanit Kaewduangdee ${ }^{\mathrm{a}}$, Arunrat Chaveerach ${ }^{\mathrm{a}}$, Tawatchai Tanee ${ }^{\mathrm{b}}$, Pornnarong Siripiyasing ${ }^{\mathrm{c}}$, \\ Runglawan Sudmoon ${ }^{\mathrm{d}, *}$ \\ a Department of Biology, Faculty of Science, Khon Kaen University, Khon Kaen 40002 Thailand \\ b Faculty of Environment and Resource Studies, Mahasarakham University, Maha Sarakham 44150 \\ Thailand \\ c Faculty of Science and Technology, Mahasarakham Rajabhat University, Maha Sarakham 44000 Thailand \\ d Faculty of Law, Khon Kaen University, Khon Kaen 40002 Thailand
}

*Corresponding author, e-mail: rungla@kku.ac.th

Received 21 Aug 2019

Accepted 16 Jun 2020

\begin{abstract}
Arbutin plays an important role as a tyrosinase inhibitor in melanogenesis and a polyphenol oxidase inhibitor in enzymatic browning reactions. In this study, we utilized GC-MS and HPLC to quantify arbutin in dried ethanol extract of leaves from Artocarpus lacucha and Artocarpus thailandicus, followed by arbutin purification and purity analysis using semipreparative HPLC and ${ }^{1} \mathrm{H}$-NMR. MTT and comet assays run on human peripheral blood mononuclear cells (PBMCs) were used to test the plant extracts for cytotoxicity and genotoxicity. The plants' biological activities were determined by colorimetric tyrosinase inhibition assay and polyphenol oxidase inhibition in enzymatic browning reaction on banana peels. Analysis by GC-MS and HPLC in the two species showed that young leaves had an arbutin content of $9.47 \%, 0.24 \mathrm{mg} / \mathrm{g}$ and $13.35 \%, 0.32 \mathrm{mg} / \mathrm{g}$, respectively, which were higher than those in mature leaves. Neither of the two species showed toxicity to PBMCs at the cellular or DNA level. Furthermore, both species were shown to have significant antioxidant and tyrosinase suppression effects $(p<0.05)$, and a solution of ground mature $A$. lacucha leaves containing $10 \%$ arbutin significantly suppressed $(p<0.05)$ brown spot formation in banana. These results provide novel and important scientific insights that could benefit human health and facilitate the post harvesting process of agricultural products. The leaf extracts of A. lacucha and A. thailandicus are promising new candidates that could be added as a whitening agent in cosmetics and a preserving agent for fruit products. The major advantage of these two species is they are recognized as a plentiful and sustainable resource with high quality.
\end{abstract}

KEYWORDS: Artocarpus lacucha, Artocarpus thailandicus, arbutin, tyrosinase, polyphenol oxidase

\section{INTRODUCTION}

Plants have long been used to promote human health and well-being through direct consumption and traditional medicine as well as through the indirect consumption of modern drugs that are developed from purified, synthetic or modified derivatives. The use of these plants in human health can be connected to their phytochemical content, and many have shown beneficial effects. For example, $\gamma$-sitosterol from the Lagerstroemia species has an antihyperglycemic activity [1]; oleamide, which is also found in the Dillenia species, improves memory recall and can function as a sleep aid and improves appetite in the elderly [2]; and phytosterols, which consist of both plant sterols and plant stanols, have the effect of lowering LDLcholesterol concentrations. These compounds naturally occur in all foods of plant origin including vegetable oils, nuts, seeds, grain products and fruits and vegetables, and a normal daily diet will include approximately 200-400 mg of these compounds [3]. However, the ideal doses of these compounds vary. Racette et al [4] suggested a $2 \mathrm{~g} / \mathrm{d}$ phytosterol supplementation, which is also recommended by the National Cholesterol Education Program to reduce LDL cholesterol. However, Cantrill and Kamamura [5] found that $150-400 \mathrm{mg} /$ day was the ideal supplementation, which indicates that the effects of consuming different quantities of phytosterols on cholesterol metabolism are still unclear [4]. 
Phytochemicals are also important ingredients in skin lightening products, which are included in cosmetics worldwide. Many types of skin lightening substances can be obtained from both natural and synthetic sources. Mechanistically, skin lightening is related to the inhibition of tyrosinase. Tyrosinase is a copper-containing enzyme that is present in melanocytes and catalyzes melanogenesis. Several chemicals are frequently used in skin lightening cosmetics, including retinoids, hydroquinone and ester derivatives, mercury salts, arbutin, kojic acid, azelaic acid, glutathione, vitamins C, E and B3, alpha hydroxyl acids (AHAs or fruit acids) and corticosteroids. However, many of these substances have been banned due to their potentially hazardous effects [6].

Heartwoods of A. lacucha have been applied for the anti-inflammatory therapy and as traditional anthelmintic agent [7] and have been shown to contain oxyresveratrol [8]. Oxyresveratrol has been proved to inhibit tyrosinase activity, thus popularly employed as skin-whitening product ingredient. Recently, Noikotr et al [9] reported detection of arbutin in A. lacucha leaf. $\beta$-Arbutin is a hydroquinone derivative that has been found in several species of plant genera, including Arctostaphylos, Bergenia, Lathyrus, Origanum, Pyrus and Vaccinium [10-14]. It serves as a tyrosinase inhibitor in the inhibition of mammalian melanogenesis and is responsible for the enzymatic browning reactions that occur in damaged fruits during postharvest handling and processing [10]. As a result, $\beta$-arbutin is used in many cosmetics, particularly in those that are aimed at lightening the skin as well as in spot treatments, creams, lotions, soaps, serums and cleansers. Its concentration in these cosmetics ranges from 7.5-27.9\% [11]. Due to patent specifications, most skin care products include plant extracts that contain arbutin such as bearberry (Arctostaphylos uvaursi), pear (Pyrus pyrifolia) and lingonberry (Vaccinium vitis-idaea) rather than pure arbutin. On the other hand, the enzymatic browning reaction also affects the color of plants and damaged fruits due to the oxidation that occurs during the postharvest processing and storage. Polyphenol oxidases (PPOs), which are also known as tyrosinases [15], catalyze the oxidation of several phenols into $o$ quinones and cause the rapid polymerization of $o$ quinones to produce black, brown or red pigments (polyphenols) that cause fruit browning $[10,16]$. Presently, $\alpha$-arbutin, which is a well-known synthetic form of arbutin, shows a greater efficiency as a skin-lightening agent than $\beta$-arbutin. It is also the strongest inhibitor of mammalian tyrosinase [17].

This study aimed to investigate these two plants and their arbutin quantity by GC-MS and HPLC, followed by arbutin purification and subsequent purity analysis using semipreparative HPLC and ${ }^{1} \mathrm{H}$-NMR. The plants that contained arbutin were tested for cytotoxicity and genotoxicity using MTT and comet assays on human peripheral blood mononuclear cells (PBMCs), respectively. The plants' biological activities were further examined using a colorimetric tyrosinase inhibition assay and by testing the polyphenol oxidase inhibition in enzymatic browning reactions on banana peels using the ground powder of mature arbutin-containing A. lacucha leaves.

\section{MATERIALS AND METHODS}

\section{Plant materials and phytochemical extraction}

Both young and mature leaves from A. lacucha and A. thailandicus were collected from the Khon Kaen University campus, rinsed and air-dried. The dried leaves were finely ground using an electric blender, and $10 \mathrm{~g}$ of each of the leaves powder was incubated in $200 \mathrm{ml}$ of $80 \%$ ethanol $(\mathrm{pH} \mathrm{3.0)}$ for $72 \mathrm{~h}$ in the dark at room temperature (this protocol was modified from Cho et al [18]). The solution was then run through filter paper, and the solvent was eliminated by a vacuum concentrator prior to the sample being redissolved in $10 \mathrm{ml}$ of distilled water. The solution was subsequently dried using a speed vacuum concentrator (LaboGene, Denmark). The dried extract powder was kept at $-20^{\circ} \mathrm{C}$ prior to the analysis of its arbutin content and biological activities as described in the methods 1-5.

\section{Phytochemical analysis by GC-MS}

The dried extract powder was dissolved in a methanol solvent at a ratio of $1: 1 \mathrm{mg} / \mathrm{ml}$, and the solution was used in the phytochemical component screening using an Agilent Technologies GC $6890 \mathrm{~N}$, MS 5973 inert mass spectrometer fused with a capillary column $(30 \mathrm{~m} \times 250 \mu \mathrm{m} \times 0.25 \mu \mathrm{m})$. Helium gas was used as the carrier at a constant flow rate of $1 \mathrm{ml} / \mathrm{min}$. The injection and mass-transferred line temperature was set at $280^{\circ} \mathrm{C}$. The oven temperature was programmed to run from $70^{\circ} \mathrm{C}$ to $120^{\circ} \mathrm{C}$ at $3^{\circ} \mathrm{C} / \mathrm{min}$, then held isothermally for $2 \mathrm{~min}$ and finally raised to $270^{\circ} \mathrm{C}$ at $5{ }^{\circ} \mathrm{C} / \mathrm{min}$. A $1-\mu l$ aliquot of the crude extract was injected in the split mode. The relative percentage of crude constituents was expressed as a percentage by peak area normalization. Component identification was conducted by comparing the obtained mass spectra with the 
reference compounds that are included in the Wiley $7 \mathrm{~N} .1$ library.

\section{Arbutin detection by HPLC}

The dried extract powder was dissolved in a methanol solvent at a ratio of $1: 1 \mathrm{mg} / \mathrm{ml}$. The solution was run through a nylon syringe filter $(13 \times 0.2 \mu \mathrm{m})$, and the filtrate was kept in the vial until it was used. Next, $20 \mu \mathrm{l}$ of filtrate was subjected to HPLC for the arbutin analysis using a Shimadzu LC-20AD (Japan) model equipped with a quaternary pump, PAD (SPD-M20A) detector and a C18 (Inertsil ODS-3) analytical column (4.6 $\mathrm{mm} \times 250 \mathrm{~mm}, 5$-micron particle size). The wavelength was set at $280 \mathrm{~nm}$. The three mobile phases were (A) $50 \%$ methanol, (B) $2 \%$ acetic acid and (C) 100\% methanol with a flow rate of $1.0 \mathrm{ml} / \mathrm{min}$. The gradient program was set to $50 \%$ methanol at the $0-5$ th min, $4: 6 \mathrm{v} / \mathrm{v}$ of $2 \%$ acetic acid and absolute methanol at the $6-45$ th min, absolute methanol at the 46-50th min and 50\% methanol at the 50-55th min. Twenty-microliter samples were injected, and the HPLC was maintained at room temperature. Absolute methanol was used as a control to detect if the extraction solvent remained in the extracts.

A standard $\beta$-arbutin (Y0000806, SigmaAldrich) preparation and analysis as well as calibration curves and correlation coefficients $\left(R^{2}\right)$ were performed. The standard was dissolved in deionized water across five serial concentrations of $0.0001,0.001,0.01,0.1$ and $1 \mathrm{mg} / \mathrm{ml}$. The solution was run through a nylon syringe filter $(13 \times 0.2 \mu \mathrm{m})$ and stored in vials for the HPLC. The linearity of the $\beta$-arbutin standards was derived from the graph plotted between the linear regression of the peak areas resulting from the HPLC analysis and the standard concentrations. The calibration equation and $R^{2}$ provided by Microsoft Excel were also utilized. The calibration equation was used to evaluate the peak areas of $\beta$-arbutin in the equation.

\section{Arbutin purification by semipreparative HPLC}

One gram of the dried extract powder was dissolved in $10 \mathrm{ml}$ of methanol. The solution was isolated by a Waters 1525 binary semipreparative HPLC pump with a 2998 photodiode array detector and a $\mathrm{C}_{18}$ (Inertsil ODS-3) analytical column (10 $\mathrm{mm} \times 250 \mathrm{~mm}, 5$-micron particle size). The wavelength was set at $280 \mathrm{~nm}$. The mobile phase consisted of $2 \%$ acetic acid and $50 \%$ methanol at a flow rate of $9.9 \mathrm{ml} / \mathrm{min}$. The gradient program was set to $2 \%$ acetic acid at the $0-5$ th min, a mixture of $2 \%$ acetic acid and $50 \%$ methanol $(90: 10 \mathrm{v} / \mathrm{v})$ at the $6-15$ th $\min , 2 \%$ acetic acid and 50\% methanol $(85: 15 \mathrm{v} / \mathrm{v})$ at the $16-20$ th min, $2 \%$ acetic acid and $50 \%$ methanol $(75: 25 \mathrm{v} / \mathrm{v})$ at the $21-26$ th $\mathrm{min}, 50 \%$ methanol at the 27-39th min and $2 \%$ acetic acid at the 40-45th min.

The $\beta$-arbutin standard was dissolved in methanol $(1 \mathrm{mg} / \mathrm{ml})$ and used for analysis by comparing sample peaks and retention times.

The isolated arbutin solution was further dried to a powder by a speed vacuum concentrator, and the purity of the arbutin powder was verified by ${ }^{1} \mathrm{H}$-NMR analysis.

\section{${ }^{1} \mathrm{H}-\mathrm{NMR}$ analysis of arbutin purity}

Five mg of the purified arbutin powder was dissolved in $5 \mathrm{ml}$ of tetradeuteromethanol $\left(\mathrm{CD}_{3} \mathrm{OD}\right)$. The solution was injected into the ${ }^{1} \mathrm{H}-\mathrm{NMR}$, and the program was recorded at $400 \mathrm{MHz}$ (Varian, Bruker). The chemical shift was measured using tetramethylsilane as an internal standard.

\section{Toxicity testing}

The dried extract powder solution was prepared by dissolving $1 \mathrm{mg}$ of the powder in $1 \mathrm{ml}$ of distilled water, then the solution was two-fold serial diluted for five levels $(1.00,0.50,0.25,0.125$ and $0.0625 \mathrm{mg} / \mathrm{ml}$ ). These concentrations were used for the MTT assay, and the concentration of $1.00 \mathrm{mg} / \mathrm{ml}$ was used for the comet assay.

Toxicity testing procedures including human peripheral blood mononuclear cells (PBMCs) preparations, cytotoxicity via MTT assay and genotoxicity via comet assay were done following Sirikhansaeng et al [1] and Chaveerach et al [19]. MTT results were shown by percentage of cell viability. Comet assay results were shown by Olive Tail Moment (OTM) which reflected the DNA damage in each of 150 cells observed measured by CASP software. The OTM values of the experiments (cells treated with the extract solutions) were compared to the values of negative control cells (untreated cells) to show statistically significant differences.

\section{Colorimetric tyrosinase inhibition}

This assay was modified from Momtaz et al [20]. A solution of $0.05 \mathrm{mg} / \mathrm{ml}$ of the dried extract powdered samples in 10\% DMSO was made. This solution was divided into two-fold serial dilutions across six levels in 0.1 M PBS ( $\mathrm{pH}$ 6.8). Positive controls consisted of $0.50 \mathrm{mg}$ of the $\alpha$ - and $\beta$-arbutin standards while negative controls consisted of a 
mixture of L-dopa and tyrosinase. Sample solutions across a range of concentrations were added to a 96-well plate at a volume of $70 \mu \mathrm{l}$ in each well, and $30 \mu \mathrm{l}$ of tyrosinase (333 unit/ $\mathrm{ml}$ in phosphate buffer, $\mathrm{pH}$ 6.8) was added to the corresponding wells. The plates were then incubated in the dark at room temperature for $5 \mathrm{~min}$. Next, $110 \mu \mathrm{l}$ of $12 \mathrm{mM} \mathrm{L}$-dopa was added to each well and incubated continuously for $30 \mathrm{~min}$. The optical density (OD) values were measured at $492 \mathrm{~nm}$. The maximum concentration inhibition was determined by measuring any significant tyrosinase inhibition relative to the tyrosinase control $(p<0.05)$. The $\mathrm{IC}_{50}$ values indicated that there was efficient tyrosinase inhibition activity.

\section{Polyphenol oxidase inhibition in the enzymatic browning reaction on banana peels using ground powder from the mature arbutin- containing A. lacucha plant}

Ripe bananas (fruits) were rinsed and air-dried at room temperature. The fruits were then divided into negative, positive or experimental groups. Each group included five bananas, and the experiment was performed in three replicates. Tap water was used as a solvent, so that it will be easy and costeffective for actual usage if the product will be commercially released. A ground powder of mature air-dried A. lacucha leaves was dissolved in tap water at three concentrations containing arbutin at $4 \%, 7 \%$ and $10 \%(29.40,51.40$ and $73.52 \mathrm{~g}$ powder $/ 100 \mathrm{ml}$ water). The positive and negative controls were $7.5 \%$ ascorbic acid and tap water, respectively. For each experiment, the bananas were soaked for $1 \mathrm{~h}$ at room temperature. The fruits were then transferred to a tray and left for $30 \mathrm{~min}$ before being exposed to sunlight for $2 \mathrm{~h}$ at $45^{\circ} \mathrm{C}$ and kept at room temperature to observe the formation of brown spots. Brown spot formation was observed by eyes, and numbers of brown spots on the banana peels were recorded each consecutive day for 10 days and analyzed to identify statistically significant $(p<0.05)$ brown spot inhibition.

\section{RESULTS}

\section{Phytochemical screening in leaf extracts of two Artocarpus species}

GC-MS was used to determine the phytochemical components in young and mature leaf extracts from A. lacucha and A. thailandicus. The young leaves of A. lacucha and A. thailandicus contained higher levels of arbutin (9.47\% and $13.35 \%$, respectively) while lower amounts were detected in the mature
Table 1 Phytochemical profiles in methanol extracts of young and mature leaf powders of A. lacucha and A. thailandicus detected by GC-MS.

\begin{tabular}{|c|c|c|c|c|c|}
\hline \multirow{3}{*}{ Compound } & \multirow{3}{*}{ Formula } & \multicolumn{4}{|c|}{ Content ( $\%$ area) } \\
\hline & & \multicolumn{2}{|c|}{ A. lacucha } & \multicolumn{2}{|c|}{ A. thailandicus } \\
\hline & & YL & ML & YL & ML \\
\hline Arbutin & $\mathrm{C}_{1}$ & 9.47 & 1.51 & 13.35 & - \\
\hline 1,4-Benzenediol & $\mathrm{C}_{36}^{1}$ & 10.66 & 3.85 & - & - \\
\hline Cytidine & $\mathrm{N}_{3} \mathrm{O}_{5}$ & - & 11.64 & 5.80 & - \\
\hline $\begin{array}{l}\text { 2,3-Dihydrobenzo- } \\
\text { furan }\end{array}$ & $\mathrm{C}_{8}^{\prime} \mathrm{H}$ & 1.85 & 1.15 & 2.03 & - \\
\hline $\begin{array}{l}\text { Ethyl alpha-D } \\
\text { glucopyranoside }\end{array}$ & $\mathrm{C}_{8} \mathrm{H}_{16} \mathrm{O}_{6}$ & 2.18 & 6.46 & 1.71 & 5.31 \\
\hline Ethyl palmitate & $\mathrm{C}_{18} \mathrm{H}_{36} \mathrm{O}_{2}$ & 12.44 & - & 4.87 & - \\
\hline Lupeol acetate & $\mathrm{C}_{32} \mathrm{H}_{52} \mathrm{O}_{2}$ & - & - & 6.68 & 6.30 \\
\hline Ethyl stearate & $\mathrm{C}_{20} \mathrm{H}_{40} \mathrm{O}_{2}^{2}$ & 3.66 & - & 1.65 & - \\
\hline Palmitic acid & $\mathrm{C}_{16} \mathrm{H}_{32} \mathrm{O}_{2}$ & 0.66 & 0.44 & 1.80 & 0.55 \\
\hline Phytol & $\mathrm{C}_{20}^{10} \mathrm{H}_{40} \mathrm{O}^{2}$ & 5.90 & 12.64 & 9.11 & 21.56 \\
\hline Phytol acetate & $\mathrm{C}_{22}^{20} \mathrm{H}_{42} \mathrm{O}_{2}$ & - & - & - & 0.84 \\
\hline 2-Palmitoylglycerol & $\mathrm{C}_{19} \mathrm{H}_{38} \mathrm{O}_{4}$ & - & - & - & 0.66 \\
\hline 4-Propylphenol & $\mathrm{C}_{9} \mathrm{H}_{12} \mathrm{O}$ & 2.39 & 5.55 & 6.22 & 4.34 \\
\hline 4-Propylresorcinol & $\mathrm{C}_{9} \mathrm{H}_{12} \mathrm{O}_{2}$ & - & - & - & 0.99 \\
\hline Quinic acid & $\mathrm{C}_{7} \mathrm{H}_{12} \mathrm{O}_{6}^{2}$ & 15.87 & 9.30 & 5.63 & - \\
\hline Squalene & $\mathrm{C}_{30} \mathrm{H}_{50}$ & 0.29 & - & - & - \\
\hline$\gamma$-Sitosterol & $\mathrm{C}_{29} \mathrm{H}_{50} \mathrm{O}$ & 2.68 & - & 4.02 & 2.03 \\
\hline Tetradecane & $\mathrm{C}_{14} \mathrm{H}_{30}$ & - & - & - & 0.61 \\
\hline$\alpha$-Tocopherol & $\mathrm{C}_{29} \mathrm{H}_{50} \mathrm{O}_{2}$ & 0.15 & - & 0.49 & 1.07 \\
\hline$\gamma$-Tocopherol & $\mathrm{C}_{28} \mathrm{H}_{48} \mathrm{O}_{2}$ & 0.26 & - & 0.45 & 0.58 \\
\hline
\end{tabular}

YL, young leaves; ML, mature leaves.

Table 2 Arbutin content in young and mature leaves of A. lacucha and A. thailandicus according to the fresh weight of the leaves that were extracted under suitable conditions to obtain the highest amount of arbutin in $1 \mathrm{~g}$ of the freeze-dried powder.

\begin{tabular}{lcccc}
\hline \multirow{2}{*}{ Sample } & \multirow{2}{*}{$\begin{array}{c}\text { Leaf } \\
\text { weight }\end{array}$} & \multicolumn{3}{c}{ Arbutin content } \\
\cline { 3 - 5 } & $(\mathrm{g})$ & $\begin{array}{c}\mathrm{X} \pm \mathrm{SD} \\
(\mathrm{mg})^{\mathrm{a}}\end{array}$ & $\begin{array}{c}\text { Conc. } \\
(\mathrm{mg} / \mathrm{ml})\end{array}$ & \%RSD \\
\hline A. lacucha (YL) & 2.19 & $0.52 \pm 0.001$ & 0.52 & 0.19 \\
A. lacucha (ML) & 2.28 & $0.43 \pm 0.001$ & 0.43 & 0.23 \\
A. thailandicus (YL) & 2.12 & $0.68 \pm 0.008$ & 0.68 & 1.17 \\
A. thailandicus (ML) & 2.36 & $0.11 \pm 0.001$ & 0.11 & 0.73 \\
\hline
\end{tabular}

${ }^{\text {a }} \mathrm{mg}$ arbutin content in the extract $\pm \mathrm{SD}$ (standard deviation), $n=3$. YL, young leaves; ML, mature leaves; Conc., concentration.

leaves of A. lacucha, and arbutin was lacking in the mature leaves of $A$. thailandicus. Additionally, key compounds such as 1,4-benzenediol, cytidine, ethyl palmitate, phytol and quinic acid are shown in Table 1. HPLC was then performed to quantify the arbutin levels. The calibration equation and correlation coefficient $\left(R^{2}\right)$ were derived from the plotted graphs using concentrations and peak areas of $\beta$-arbutin as $y=7 \times 10^{6} x+18531$ and 1 for the $R^{2}$ value. Chromatograms of the standard $\beta$ arbutin and the studied samples including extracts from young and mature leaves of A. lacucha and 

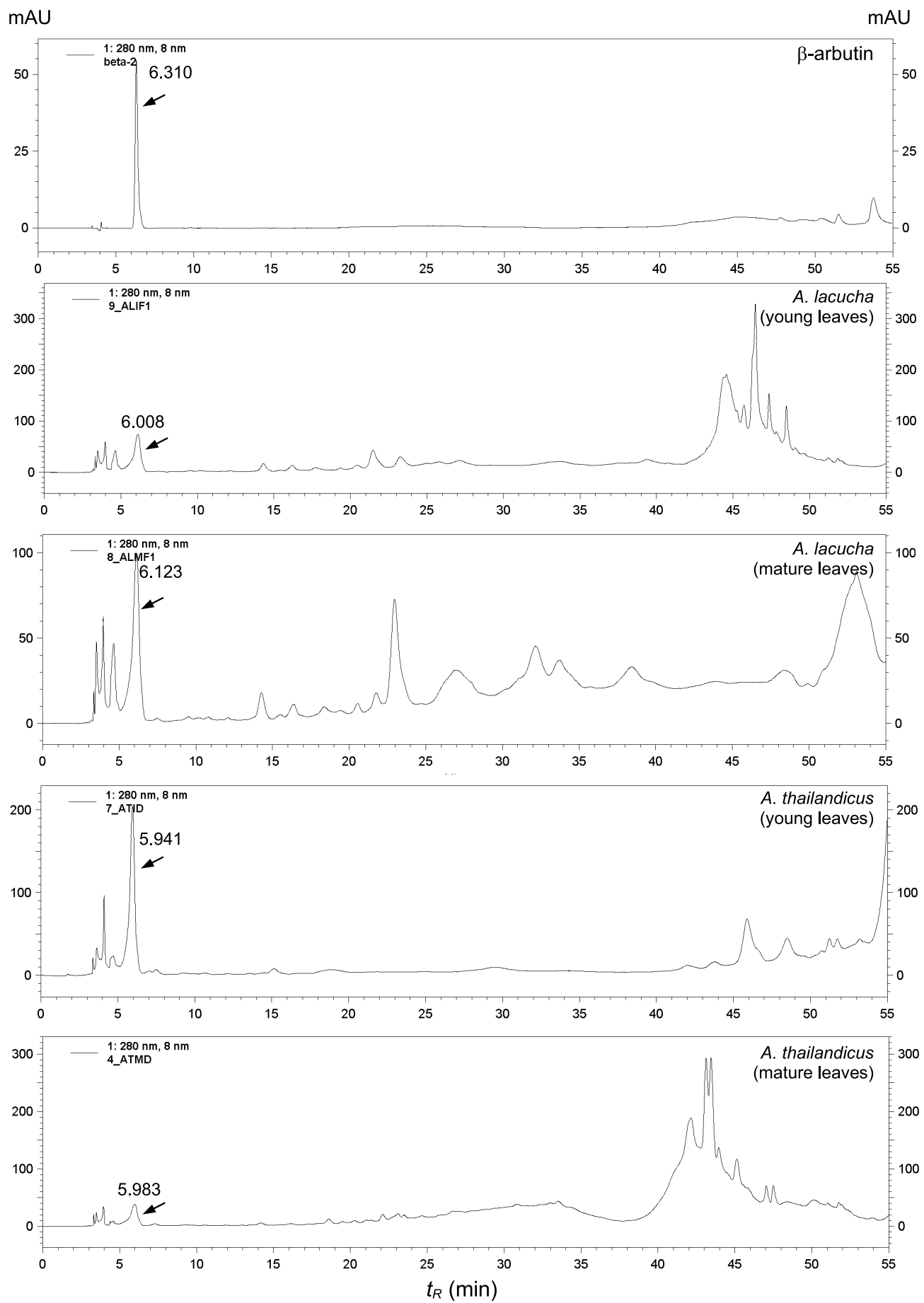

Fig. 1 HPLC chromatogram showing the peak area (arrow) and retention time $\left(t_{R}\right)$ of the $\beta$-arbutin standard and the studied samples, which exhibited arbutin quantities in the young and mature leaf extracts of A. lacucha and A. thailandicus.

A. thailandicus are shown in Fig. 1. The quantity of arbutin was calculated by substituting the peak areas of the samples in the calibration equation. The quantity and concentration of arbutin in young and mature leaves were $0.52,0.43,0.68$ and $0.11 \mathrm{mg}$ and $0.52,0.43,0.68$ and $0.11 \mathrm{mg} / \mathrm{ml}$ in A. lacucha 


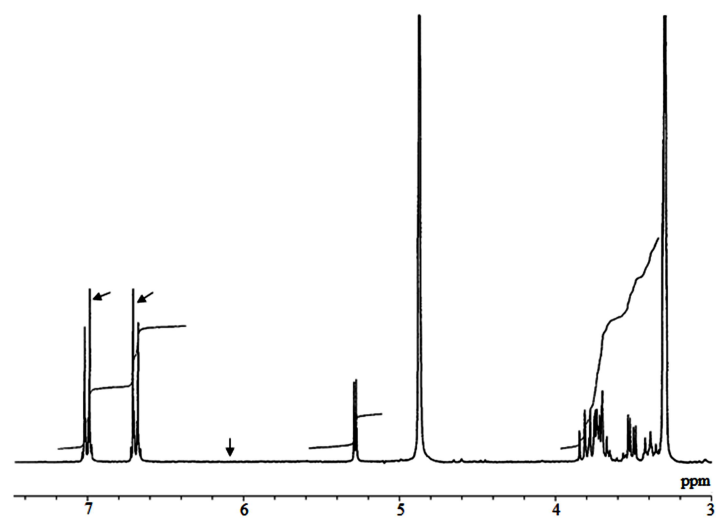

Fig. $2{ }^{1}$ H-NMR spectrum of arbutin (arrows) from leaf extracts of two Artocarpus species, namely A. lacucha and A. thailandicus, where the flat baseline (arrow) indicates an arbutin purity at $>99 \%$.

and $A$. thailandicus, respectively. The relative standard deviation (RSD) values fell between 0.192\% and $1.17 \%$, which demonstrates the credibility of the method (Table 2).

Arbutin was isolated and purified by semipreparative HPLC from the fraction that was contaminated with mobile phase. The fraction was dried by a speed vacuum concentrator to generate the arbutin powder. The purity of the arbutin powder was verified by ${ }^{1} \mathrm{H}$-NMR analysis. The ${ }^{1} \mathrm{H}$-NMR spectrum of the arbutin fraction was measured in $\mathrm{CD}_{3} \mathrm{OD}$ and revealed by the glycoside derivative of hydroquinone (an arbutin derivative). The flat baseline indicated that the purity of the arbutin was higher than $99 \%$ (Fig. 2).

The solutions of extract powder from young and mature leaf powder were tested by MTT assay. The results (Fig. 3) indicated that there were no toxic effects on PBMCs as shown by the lack of IC $_{50}$ values and the high cell viability percentages ranging between $67.43 \pm 0.20$ and $91.69 \pm 0.15$. Furthermore, $\alpha$ - and $\beta$-arbutin standards at $0.31-5.00 \mathrm{mg} / \mathrm{ml}$ also showed very high PBMC viability percentages that ranged between $89.67 \pm 0.23$ and $97.72 \pm 0.24$ and $77.37 \pm 0.20$ and $98.05 \pm 0.25$, respectively. An indepth genotoxicity evaluation was performed using a comet assay with the maximum concentration ( $1 \mathrm{mg} / \mathrm{ml}$ powder). These assays showed that the powder did not induce any significant DNA damage $(p>0.05)$ compared to the negative control as indicated by the OTM values (Table 3 ) and the comet assay images (Fig. 4).

Tyrosinase suppression activity was verified by using the sample powder in the colorimetric ty-
Table 3 The level of DNA damage expressed as an OTM in PBMCs after treatment with $\alpha$ - and $\beta$-arbutin standards and the powder solution from $A$. lacucha and A. thailandicus.

\begin{tabular}{lccc}
\hline Sample & $\begin{array}{c}\text { Conc. } \\
(\mathrm{mg} / \mathrm{ml})\end{array}$ & OTM & $p$-value \\
\hline a-Arbutin & 5.00 & $0.012 \pm 0.02$ & 0.1705 \\
Negative control & - & $0.011 \pm 0.02$ & \\
$\beta$-Arbutin & 5.00 & $0.015 \pm 0.02$ & 0.1460 \\
Negative control & - & $0.011 \pm 0.02$ & \\
A. lacucha (YL) & 1.00 & $0.012 \pm 0.02$ & 0.6184 \\
Negative control & - & $0.011 \pm 0.02$ & \\
A. lacucha (ML) & 1.00 & $0.056 \pm 0.18$ & 0.1910 \\
Negative control & - & $0.050 \pm 0.12$ & \\
A. thailandicus (YL) & 1.00 & $0.053 \pm 0.12$ & 0.2792 \\
Negative control & - & $0.050 \pm 0.12$ & \\
A. thailandicus (ML) & 1.00 & $0.051 \pm 0.16$ & 0.2530 \\
Negative control & - & $0.050 \pm 0.12$ & \\
\hline
\end{tabular}

YL, young leaves; ML, mature leaves; Conc., working concentration; OTM, Olive tail moment.

rosinase inhibition assay. The percentages of tyrosinase inhibition were between $5.30 \pm 0.02-$ $77.69 \pm 0.05$ and $1.15 \pm 0.06-78.83 \pm 0.002$ for $\alpha-$ and $\beta$-arbutin, respectively. The young and mature leaves of $A$. lacucha and $A$. thailandicus showed tyrosinase inhibition percentages of $33.68 \pm 0.012-93.91 \pm 0.001,10.63 \pm 0.022-93.60$ $\pm 0.004,21.51 \pm 0.006-94.56 \pm 0.002$ and $3.88 \pm$ 0.014-94.09 \pm 0.002 , respectively, at concentrations of $0.016-0.50 \mathrm{mg} / \mathrm{ml}$ (Fig. 5). The $\mathrm{IC}_{50}$ values of $\alpha$-arbutin and $\beta$-arbutin were 0.22 and $0.31 \mathrm{mg} / \mathrm{ml}$, and $0.11,0.12,0.07$ and $0.11 \mathrm{mg} / \mathrm{ml}$ for the young and mature leaves of $A$. lacucha and A. thailandicus, respectively (Fig. 5). Therefore, these results indicated a significant tyrosinase inhibition activity $(p<0.05)$.

The ground powder from the mature leaves of A. lacucha was used to inhibit the formation of brown spots on green banana peels during the post harvesting period. The results showed that brown spot formation occurred on day 5 and that the spots became darker and more plentiful by day 10 . The number of brown spots on the green fruits that were soaked in water, $7.5 \%$ ascorbic acid and the ground powder solutions of $4 \%, 7 \%$ and $10 \%$ arbutin was $4.30 \pm 1.42,3.80 \pm 1.03,3.90 \pm 0.87,3.80 \pm 1.55$ and $2.00 \pm 0.78$, respectively. Therefore, the $10 \%$ arbutin ground powder solution was shown to significantly suppress the formation of brown spots under UV exposure. Examples of bananas from each experiment at day 10 were shown in Fig. S1. 

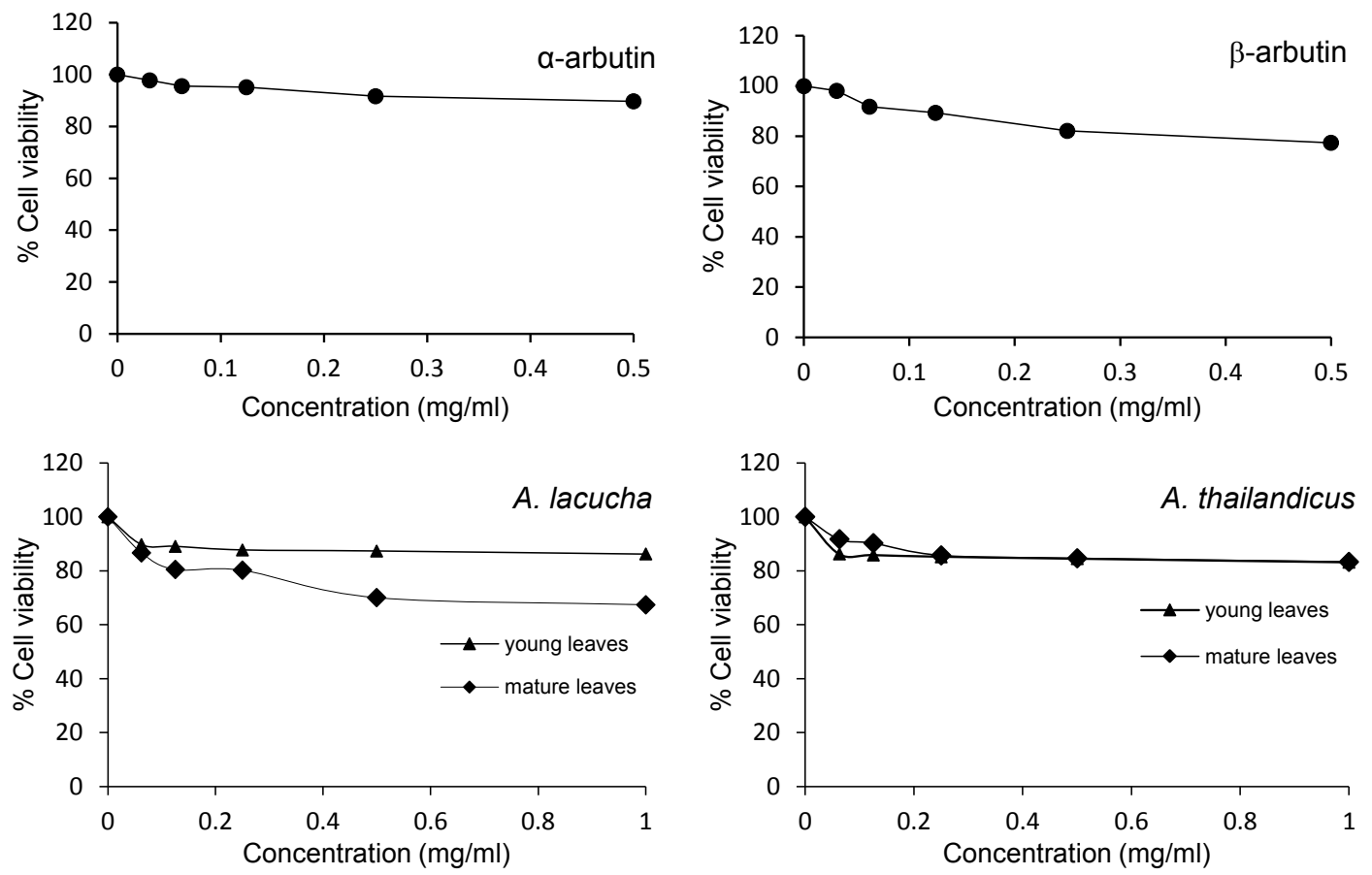

Fig. 3 Cytotoxicity testing with the MTT assay of $\alpha$ - and $\beta$-arbutin standards and the crude arbutin from young and mature leaves of A. lacucha and A. thailandicus exhibited high percentage of cell viability without $\mathrm{IC}_{50}$ value.
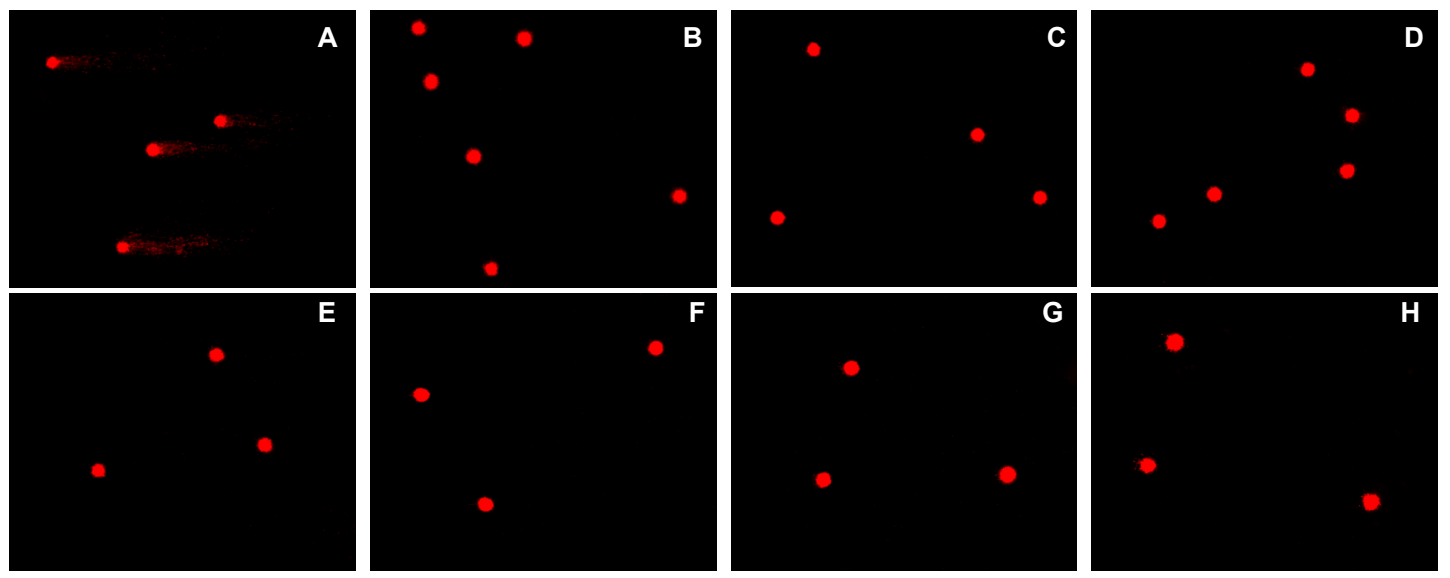

Fig. 4 Comet assay images of PBMCs $(200 \times)$; positive control (A), negative control (B) and the experimental group including the standard as $\alpha$-arbutin (C), $\beta$-arbutin (D), young leaf powder of A. lacucha (E), mature leaf powder of A. lacucha (F), young leaf powder of A. thailandicus (G) and mature leaf powder of $A$. thailandicus $(\mathrm{H})$.

\section{DISCUSSION}

This study profiled the arbutin content of two plant species, A. lacucha and A. thailandicus and found that they contained a sufficient amount to be successfully incorporated as an ingredient in human products such as skin lightening cosmetics and as an agricultural preservative to protect products like fruits during transportation from their source to the market. A previous publication that phytochemically screened A. lacucha using GC-MS and reported on its toxicity found $21.61 \%$ arbutin content [18]. However, in our study, the A. lacucha plants were grown in different areas under different weather conditions and seasons. Additionally, both young and mature leaves were included in all experiments described in this study. The plant samples were 


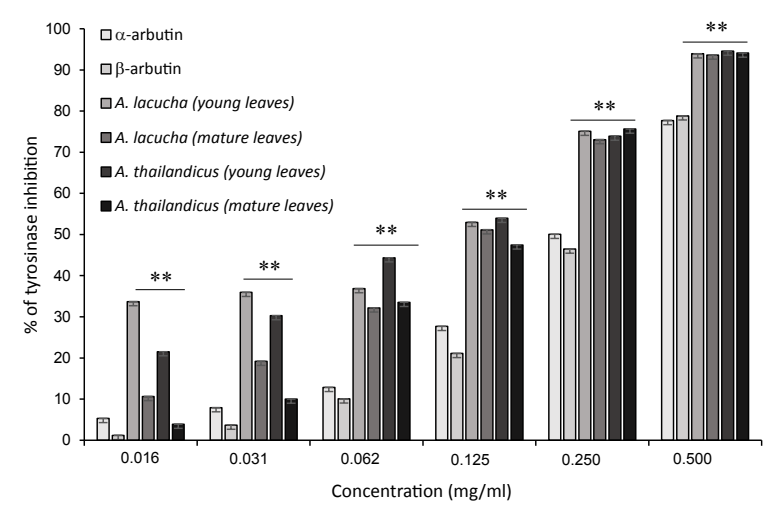

Fig. 5 The percentage of tyrosinase inhibition activity of $\alpha$-arbutin, $\beta$-arbutin, and the young and mature leaves of the A. lacucha and A. thailandicus plants. ** indicated significant inhibition $(p<0.05)$.

extracted using a protocol that was modified from Cho et al [18], which reported high arbutin yields from the extraction. Finally, the extracts were used to generate $1 \mathrm{~g}$ of freeze-dried powder from $2.19,2.28,2.12$ and $2.36 \mathrm{~g}$ of young and mature A. lacucha and $A$. thailandicus leaves, respectively. The powders were then used in all reported experiments except for the polyphenol oxidase inhibition tests on banana peels. However, we did attempt to use the ground powder from the arbutin-containing mature A. lacucha plant on the banana peels as a prototype for fruit preservation.

The GC-MS chromatograms revealed that the young leaves of both species contained high levels of arbutin $(9.47 \%$ in $A$. lacucha and $13.35 \%$ in A. thailandicus) (Table 1), and the HPLC results showed that the powder isolated from the young leaves had a higher arbutin content than the powder isolated from the mature leaves $(0.52 \mathrm{mg}$ and $0.68 \mathrm{mg}$ in $1 \mathrm{~g}$ of freeze-dried powder, respectively) of A. lacucha and $A$. thailandicus (Table 2). The arbutin content in the two Artocarpus species was sufficiently high enough to be used in a variety of products and could be isolated at a high quality and a purity of $99 \%$ by semipreparative HPLC and ${ }^{1} \mathrm{H}-\mathrm{NMR}$. Compared to the $\alpha$-arbutin and $\beta$-arbutin standards, the plant powder samples showed no cytotoxicity as reflected by the high cell viability percentages or genotoxicity. The MTT and comet assays that were used to evaluate cellular toxicity with the cultured PBMCs are well-established and reliable methods at the preclinical level [22-24], and they have been used in many publications $[1,19,21,25]$. Collectively, we showed that these plant species can be used as ingredients for products in both purified and crudely extracted forms. The measured arbutin content described in this study cannot fully explore the potential uses of these plants on its own, and further research of these two Artocarpus species is required to better understand their biological activities, which should include tyrosinase suppression and polyphenol oxidase inhibition tests. The young and mature leaf powders demonstrated significant tyrosinase suppression activity $(p<0.05)$, and these results are shown in Fig. 5. This activity showed that the crude Artocarpus powder contained enough arbutin to inhibit melanogenesis and that these powders can be added to cosmetics to lighten the skin. The Scientific Committee on Consumer Safety (SCCS) [25] considers a $\beta$-arbutin concentration of up to $7 \%$ to be the safe range for face creams [6], so the quantity of arbutin found in these two plant species, even in their crude form, is more than enough. Many other skin care products contain plant extracts that contain arbutin, including bearberry (Arctostaphylos uva-ursi), pear (Pyrus pyrifolia) and lingonberry (Vaccinium vitis-idaea) rather than pure arbutin due to patent specifications. Additionally, we aimed to create a prototype fruit preservative by inhibiting the enzymatic browning reaction during the post harvesting period for bananas and other fruits when they are transported from farms to the markets. To that end, we found that the mature A. lacucha plant was easier to collect than $A$. thailandicus, and $2.28 \mathrm{~g}$ of ground powder that contained $0.43 \mathrm{mg}$ of arbutin was used for the polyphenol oxidase inhibition testing. The results indicated that a $10 \%$ arbutin from the ground powder solution was able to significantly suppress the formation of brown spots under solar activation.

In this study, we report on novel and important scientific findings that can be used to benefit human health and improve the resilience of agricultural products during transportation. A. lacucha and A. thailandicus represent novel choices that can now be considered when plants containing arbutin are needed, adding to the existing plant options such as Arctostaphylos, Bergenia, Lathyrus, Origanum, Pyrus and Vaccinium. These two plant species can be used to provide ingredients for cosmetics and for fruit preservation.

\section{Appendix A. Supplementary data}

Supplementary data associated with this article can be found at http://dx.doi.org/10.2306/ scienceasia1513-1874.2020.053. 
Acknowledgements: This research was financially supported by Research and Academic Services, Khon Kaen University.

\section{REFERENCES}

1. Sirikhansaeng P, Tanee T, Sudmoon R, Chaveerach A (2017) Major phytochemical as $\gamma$-sitosterol disclosing and toxicity testing in Lagerstroemia species. EvidBased Compl Alt Med 2017, ID 7209851.

2. Thooptianrat T, Chaveerach A, Sudmoon R, Tanee T, Liehr T, Babayan N (2017) Screening of phytochemicals and toxicity of medicinal plants, Dillenia species, reveals potential natural product resources. $J$ Food Biochem 41, ID 12363.

3. Ras RT, Geleijnse JM, Trautwein EA (2014) LDLcholesterol-lowering effect of plant sterols and stanols across different dose ranges: a meta-analysis of randomised controlled studies. Brit J Nutr 112, 214-219.

4. Racette SB, Lin X, Lefevre M, Spearie CA, Most MM, Ma L, Ostlund Jr RE (2009) Dose effects of dietary phytosterols on cholesterol metabolism: a controlled feeding study. Am J Clin Nutr 91, 32-38.

5. Cantrill R, Kamamura Y (2008) Phytosterols, phytostanols and their esters, chemical and technical assessment. Available at: www.fao.org/fileadmin/ templates/agns/pdf/jecfa/cta/69/Phytosterols.pdf.

6. Burger P, Landreau A, Azoulay S, Michel T, Fernandez X (2016) Skin whitening cosmetics: feedback and challenges in the development of natural skin lighteners. Cosmetics 3, ID 36.

7. Hari A, Revikumar KG, Divya D (2014) Artocarpus: a review of its phytochemistry and pharmacology. $J$ Pharma Search 9, 7-12.

8. Tengamnuay $\mathrm{P}$, Pengrungruangwong K, Pheansri I, Likhitwitayawuid K (2006) Artocarpus lakoocha heartwood extract as a novel cosmetic ingredient: evaluation of the in vitro anti-tyrosinase and in vivo skin whitening activities. Int J Cosmetic Sci 28, 269-276.

9. Noikotr K, Chaveerach A, Sudmoon R, Tanee T, Patarapadungkit N (2018) Phytochemicals, cytotoxicity and genotoxicity of three Artocarpus species firstly reveal arbutin in A. lacucha. ScienceAsia 44, 170-178.

10. Chang TS (2009) An updated review of tyrosinase inhibitors. Int J Mol Sci 10, 2440-2475.

11. Pop C, Vlase L, Tamas M (2009) Natural resources containing arbutin, determination of arbutin in the leaves of Bergenia crassifolia (L.) Fritsch. acclimated in Romania. Not Bot Horti Agrobo 37, 129-132.

12. Lukas B, Schmiderer C, Mitteregger U, Novak J (2010) Arbutin in marjoram and oregano. Food Chem 121, 185-190.

13. Lee BD, Eun JB (2012) Optimum extraction conditions for arbutin from Asian peal peel by supercritical fluid extraction (SFE) using Box-Behnken design. $J$ Med Plant Res 6, 2348-2364.

14. Pizzorno JE, Murray MT (2013) Textbook of Natural Medicine, Churchill Livingstone, Elsevier Inc., North Carolina.

15. Mayer AM (2006) Polyphenol oxidases in plants and fungi: going places? A review. Phytochem 67, 2318-2331.

16. Taranto F, Pasqualone A, Mangini G, Tripodi P, Miazzi MM, Pavan S, Montemurro C (2017) Polyphenol oxidases in crops: biochemical, physiological and genetic aspects. Int J Mol Sci 18, E377.

17. Couteau C, Coiffard L (2016) Overview of skin whitening agents: drugs and cosmetic products. Cosmetics 3, ID 27.

18. Cho JY, Park KY, Lee KH, Lee HJ, Lee SH, Cho JA, Kim WS, Shin SC, et al (2011) Recovery of arbutin in high purity from fruit peels of pear (Pyrus pyrifolia Nakai). Food Sci Biotechnol 20, 801-807.

19. Chaveerach A, Tanee T, Patarapadungkit N, Khamwachirapithak P, Sudmoon R (2016) Cytotoxicity and genotoxicity of Allamanda and Plumeria species. ScienceAsia 42, 375-381.

20. Momtaz S, Mapunya BM, Houghton PJ, Edgerly C, Hussein H, Naidoo S, Lall N (2008) Tyrosinase inhibition by extracts and constituents of Sideroxylon inerme L. stem bark, used in South Africa for skin lightening. $J$ Ethnopharmacol 119, 507-512.

21. Rollin BE (2003) Toxicology and new social ethics for animals. Toxicol Pathol 31, 128-131.

22. Doke SK, Dhawale SC (2015) Alternatives to animal testing: A review. Saudi Pharm J 23, 223-229.

23. PCRM (2013) Animal Testing and Alternatives. Physicians Committee for Responsible Medicine, Wisconsin, Washington DC. Available at: www.pcrm.org/ ethical-science/animal-testing-and-alternatives

24. Sanubol A, Chaveerach A, Tanee T, Sudmoon R (2017) Pre-clinical evaluation of extracts and essential oils from betel-like scent Piper species identified potential cancer treatment. Afr J Tradit Complem 14, 89-102.

25. SCCS (2015) Opinion on $\alpha$-arbutin, Scientific Committee on Consumer Safety, SCCS/1552/15. 
Appendix A. Supplementary data

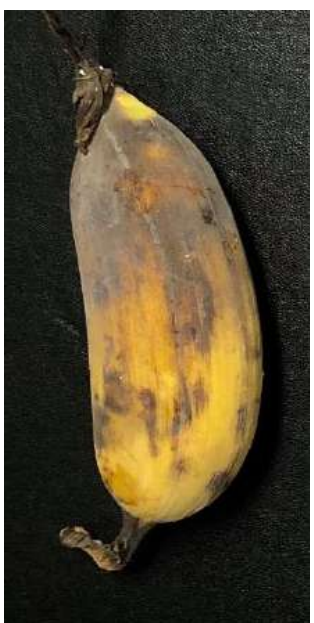

Tap water

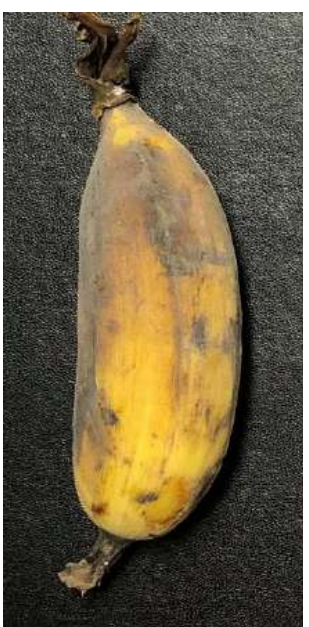

$7.5 \%$ ascorbic acid

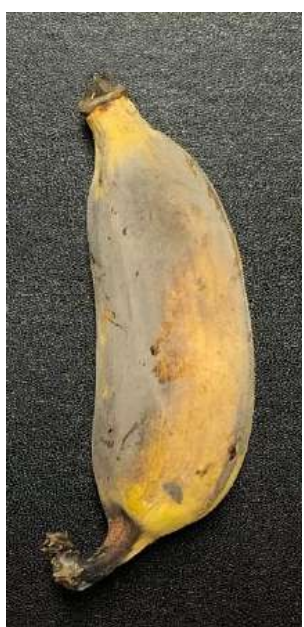

$4 \%$ crude solution

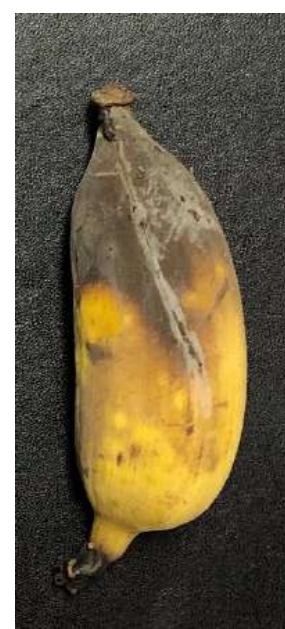

$7 \%$ crude solution

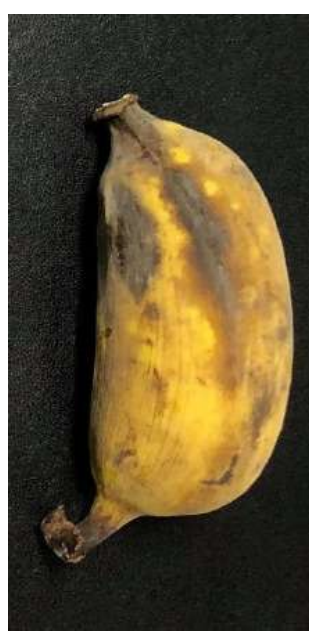

$10 \%$ crude solution

Fig. S1 Measurements of brown spot formation in banana fruits that were treated with a ground powder solution made from the leaves of A. lacucha compared to the controls of tap water and $7.5 \%$ ascorbic acid. 